\title{
ИССЛЕДОВАНИЕ СВОЙСТВ ВОДНО-СПИРТОВЫХ ЭМУЛЬСИЙ ПОДСОЛНЕЧНОГО МАСЛА МУЛЬТИСЕНСОРНОЙ СИСТЕМОЙ ПРИ РАЗЛИЧНЫХ ТЕМПЕРАТУРАХ
}

\author{
А. В. Фёдоров, Д. О. Кирсанов, А. В. Легин, И. А. Лисицына, С. М. Волков, \\ А. Г. Новосёлов, Ю. А. Поздеева, Е. А. Еловегина
}

Статья посвящена нахождению оптимального температурного режима для проведения исследований водно-спиртовых эмульсий подсолнечного масла методом мультисенсорной потенциометрии. Перед выпуском подсолнечного масла с производства проводится ряд долговременных и трудоемких анализов для определения основных параметров качества. Метод мультисенсорной потенциометрии, в свою очередь, позволяет за одно измерение получить сразу четыре основных показателя качества масла, таких как кислотное число, перекисное число, анизидиновое число и содержание токоферолов. Такой метод является перспективным аналитическим методом определения качественных и количественных свойств различных пищевых продуктов. Он основан на измерении разности потенциалов между электродом сравнения и аналитом с последующей обработкой полученных откликов. Для получения более точных измерений, полученных методом мультисенсорной потенциометрии, необходимо подобрать температурные условия проведения анализа, $m$. к. состав исследуемой эмульсии содержит изопропиловый спирт, воду и растительное масло, у которых при изменении температуры могут меняться такие свойства, как растворимость и летучесть. Исходя из этого, было проведено исследование по выбору оптимальной температуры проведения анализа, при которой получаемые показатели будут иметь минимальное отклонение, и позволят находить по ним основные критерии качества подсолнечного масла. В ходе работы был проведен ряд опытов с различными образцами подсолнечного масла и найдена оптимальная температура для проведения анализа.

Ключевые слова: подсолнечное масло, ПРМ - пищевое растительное масло, аналитические методы, мультисенсорные системы, мультисенсорная потенциометрия, водноспиртовая эмульсия, воспроизводимость сенсора, разность потенциалов.

\section{ВВЕДЕНИЕ}

В масложировом секторе пищевой промышленности России производство подсолнечного масла имеет наибольшую долю, которая в процентном выражении относительно других видов пищевых растительных масел (ПРМ) составляет около $65 \%$. В натуральном выражении на внутренний и внешний потребительский рынок ежегодно поставляется приблизительно 4 миллиона тонн масла, добываемого из семян подсолнечника. Поэтому научные исследования, направленные на разработку инновационных средств контроля состава технологических потоков и качества готовой продукции, являются актуальными с точки зрения повышения эффрективности производства ПРМ, обеспечивающего продовольственную безопасность РФ и регламентируемого Федеральным законом № 90-Ф3 от 24.06.2008 г.

В пищевой промышленности достаточно широко используются спектральные методы контроля качества производимой продукции, такие как ИК-, ЯМР-спектроскопия, спектрофотометрия $[1,20]$.

Для определения нормируемых показателей качества ПРМ [2] - кислотного и перекисного чисел - используется потенциометрическое титрование [3, 4], которое основано на измерении разности потенциалов между электродом сравнения и рабочим электродом, размещенным в жидкой фазе, содержащей целевой компонент. Потенциометрический метод в данной фрорме является косвенным способом определения концентрации окисленных компонентов ПРМ и свободных жирных кислот, для реализации которого требуется значительное количество безвозвратно расходуемых материалов, используемых в методике определения перекисного и кислотных чисел ПРМ. Более того, при проведении длительных серий аналитических определений качества ПРМ, эфффективность функционирования электродов, выполненных из благородных металлов, заметно снижается. Аналогичные проблемы могут возникнуть и при использовании вольтамперометриче- 
А. В. ФЁДОРОВ, Д. О. КИРСАНОВ, А. В. ЛЕГИН, И. А. ЛИСИЦЫНА, С. М. ВОЛКОВ, А. Г. НОВОСЁЛОВ, Ю. А. ПОЗДЕЕВА, Е. А. ЕЛОВЕГИНА

ского метода в мультисенсорном варианте [5].

Устойчивость ПРМ к окислению определяется при помощи электродов различной конструкции, измеряющих электропроводность дистиллированной воды, которая абсорбирует летучие продукты окисления ПРМ, образующиеся при их нагревании или окислении [6].

В работе [7] исследовали динамику окисления масла грецкого ореха при помощи анализаторов на основе модифицированных пьезокварцевых резонаторов (пьезосенсоров), которые фиксировали наличие летучих продуктов окисления над слоем анализируемого образца. При использовании этого косвенного метода определения степени окисленности ПРМ получали удовлетворительные корреляции результатов измерений с перекисными и кислотными числами при их значениях более 7 (1/2 О моль/кг), а кислотных чисел - более 8 (мг $\mathrm{NaOH} /$ г), соответственно.

Известны опытные методики исследования свойств ПРМ, основанные на измерении их диэлектрической проницаемости и удельной электрической проводимости [8]. При этом на образцы ПРМ воздействовали электромагнитным полем с частотой от 1кГц до 100 кГц, а затем по установленным характеристическим частотам и характеристическим активным проводимостям, использованным в качестве изменяющихся параметров, определяли ненормируемый критерий качества ПРМ «глубина очистки масла».

В работе [9] исследовали влияние переменного электрического тока с различной частотой на образцы ПРМ, помещённые в конденсатор. Амплитуда подаваемого тока изменялась в интервале $4 \div 12 \mathrm{~B}$, а частота - в интервале $0,5 \div 3500$ Гц. Полученные данные подвергались преобразованию Фурье. При этом была обнаружена зависимость величины амплитуды тока, а также амплитуд Фурьеспектров различных образцов подсолнечного масла от содержания олеиновой кислоты в триглицеридах ПРМ.

Довольно интенсивное развитие в сорере качественного и количественного анализа продуктов питания за последние годы получил метод мультисенсорной потенциометрии. В работах $[10,18]$ изложены принципы реализации этого метода применительно к широкому кругу аналитических задач и требования к сенсорам. Представленное уравнение Никольского (1) описывает отклик потенциометрических сенсоров в водных растворах с учё- том влияния температуры на разность потенциалов между электродом сравнения и измерительным электродом.

$$
E=E^{0}+\frac{R T}{z_{i} \cdot F} \cdot \ln \left(a_{i}+\sum_{j} K_{i j}\left(a_{j}\right)^{\frac{z_{i}}{z_{j}}}\right),
$$

где $E$ - разность потенциалов (эдс) электрохимической ячейки, состоящей из электрода сравнения и измерительного электрода; - стандартный потенциал; - газовая постоянная; - абсолютная температура; $F$ - постоянная Фарадея; $z_{i}$ и $z_{j}$ - заряды основного и мешающего ионов соответственно; $K_{i j}$ - коэфффициент селективности электрода к основному иону $i$ в присутствии мешающего иона $j$.

Кроме того, авторами этого обзора предложен эмпирический метод оценки «перекрёстной чувствительности», в котором для оценки воспроизводимости электродных характеристик используется значение стандартного отклонения, рассчитанное по параллельным измерениям потенциалов.

Для определения ненормируемых параметров качества ПРМ проводились исследования [11] различных образцов ПРМ с использованием массива электродов, выполненных по технологии и из материалов, представленных в $[12,13,14]$. На модельной установке были получены численные значения разности потенциалов между электродом сравнения и каждым из электродов массива в гомогенном водно-спиртовом экстракте анализируемого образца растительного масла. После математической обработки результатов измерений, с использованием различных методов хемометрики, была показана возможность распознавания образцов «прогорклого» и «товарного» растительных масел на основе откликов сенсоров.

Такая же методика измерения потенциалов с использованием массива сенсоров применялась для определения зависимости между составом гомогенных водно-спиртовых экстрактов оливковых масел и их качеством, в том числе по месту произрастания масличных культур $[15,16]$. Метод мультисенсорной потенциометрии, использованный для определения индивидуальных характеристик исследованных образцов оливковых масел, показал возможность их классификации по широкому спектру не регламентируемых параметров качества.

При условии решения задач подбора эффективного массива сенсоров, их кондиПОЛЗУНОВСКИЙ ВЕСТНИК № 22018 


\section{ИССЛЕДОВАНИЕ СВОЙСТВ ВОДНО-СПИРТОВЫХ ЭМУЛЬСИЙ ПОДСОЛНЕЧНОГО МАСЛА МУЛЬТИСЕНСОРНОЙ СИСТЕМОЙ ПРИ РАЗЛИЧНЫХ ТЕМПЕРАТУРАХ}

ционирования и отмывки, метод мультисенсорной потенциометрии имеет превосходное сочетание технических и экономических характеристик. Этот метод обладает высокой чувствительностью к широкому спектру различных аналитов, встречающихся в продуктах питания. За один цикл измерений в течение нескольких минут могут быть определены сразу несколько возможных критериев качества ПРМ. Для его реализации требуется существенно меньшее количество пробы исследуемого образца; стоимость оборудования и программного обеспечения сравнительно невысокая; малый ассортимент расходуемых материалов при этом, используемые растворители могут быть легко регенерированы для повторного применения. Эти параметры эффрективности могут служить обоснованием разработки коммерческого проекта автоматизированного устройства на основе уже существующих модельных образцов.

Исследование гетерогенных жидкофразных систем «прямых» водно-спиртовых эмульсий ПРМ методом мультисенсорной потенциометрии является перспективным направлением для разработки методики совмещённого экспресс-анализа нормируемых показателей качества ПРМ, при условии дополнительной оптимизации температурных условий измерений разности потенциалов, с учётом технологии производства исследуемых образцов ПРМ. При этом воспроизводимость откликов сенсоров является важной характеристикой эффрективности использования метода мультисенсорной потенциометрии для решения конкретных аналитических задач $[10,18]$. Для оценки воспроизводимости откликов сенсоров используется стандартное отклонение параллельных измерений для каждого сенсора. Кроме этого, для общей характеристики условий измерений образцов ПРМ должны быть рассчитаны суммы этих стандартных отклонений для всего массива. Поэтому комплексная оценка значимости факторов температуры и технологии получения образцов ПРМ и их влияния на воспроизводимость откликов сенсоров требует более подробного изучения. С учётом того, что для построения многомерных градуировочных моделей используются серии образцов конкретных видов растительных масел, определять характер зависимости воспроизводимости от температуры и способа получения растительных масел следовало бы, используя численные значения результатов сложения ПОЛЗУНОВСКИЙ ВЕСТНИК № 22018 суммарных стандартных отклонений всего массива для всех образцов серии при каждой из температур. При этом количество образцов в каждой серии может быть различным. Следовательно, для определения характера влияния температуры и способа получения растительных масел на воспроизводимость откликов сенсоров в сериях с любым количеством образцов необходимо строить функциональную зависимость среднего значения суммарных стандартных отклонений потенциалов сенсоров массива от температуры для образцов конкретной серии. Причём функциональные зависимости средних значений суммарных стандартных отклонений потенциалов сенсоров массива от температуры для образцов нерафинированного масла и для образцов рафинированного масла должны быть построены в одном числовом пространстве, но независимо друг от друга.

Целью настоящего исследования является определение характера комплексного влияния температуры в электрохимической ячейке и различий в технологии производства образцов подсолнечного масла на воспроизводимость потенциалов сенсоров, измеренную как среднее значение суммарных стандартных отклонений потенциалов всего массива в гетерогенных системах - водноспиртовых эмульсиях подсолнечного масла. Эти данные необходимы для дальнейшей разработки методики применения мультисенсорных систем в производственных условиях.

\section{ЭКСПЕРИМЕНТАЛЬНАЯ ЧАСТЬ}

На предварительном этапе исследований нами был сформирован модельный массив сенсоров из электродов на основе высокочувствительных полимерных плёнок, а в качестве компонентов эмульсии использовались дистиллированная вода, изопропиловый спирт и различные виды ПРМ, например, подсолнечное масло, высокоолеиновое подсолнечное масло, соевое масло, рапсовое масло и оливковое масло. Математическая обработка полученных численных значений потенциалов отдельных сенсоров, проведённая аналогично методике [11], позволила в многомерном математическом пространстве идентифицировать различные типы масел и их смеси, что подтвердило перспективность выбранного направления исследований свойств водно-спиртовых эмульсий ПРМ методом мультисенсорной потенциометрии. Однако выбранный массив сенсоров проявил недостаточную устойчивость к компонентам жиросодержащей эмульсии и промывочным 
А. В. ФЁДОРОВ, Д. О. КИРСАНОВ, А. В. ЛЕГИН, И. А. ЛИСИЦЫНА, С. М. ВОЛКОВ, А. Г. НОВОСЁЛОВ, Ю. А. ПОЗДЕЕВА, Е. А. ЕЛОВЕГИНА

реагентам. Для решения задач настоящего исследования был сформирован массив из 12 твердотельных электродов различного состава, изготовленных с использованием технологий $[17,18]$. Предварительные измерения потенциалов этих сенсоров в маслосодержащей водно-спиртовой эмульсии образцов различных ПРМ проводились при сезонных температурах помещений $17^{\circ} \mathrm{C} \pm 1^{\circ} \mathrm{C}$, а так же при $22{ }^{\circ} \mathrm{C} \pm 1{ }^{\circ} \mathrm{C}$. При этом были оптимизированы условия кондиционирования, отмывки электродов и подобраны концентрации компонентов, подтверждена эффрективная работа 7 сенсоров из 12, входивших в первоначальный массив. В ходе проведения экспериментальных исследований массив сенсоров из твердотельных электродов показал высокую устойчивость к воздействию жиросодержащей водно-спиртовой эмульсии и промывочных реагентов.

В качестве компонентов прямой эмульсии использовался изопропиловый спирт и вода в интервале соотношений от 40:60 до 60:40 (объёмных \%), растительные масла в количестве $0,1 \div 1,0 \%$ к общему объёму эмульсии.

Промывка электродов проводилась поочерёдно: гексаном, водным раствором поверхностно-активного вещества (ПАВ) и дистиллированной водой в течение 2-3 минут.

Математическое моделирование данных, полученных при температуре $22{ }^{\circ} \mathrm{C} \div 1^{\circ} \mathrm{C}$, поз- воляло в многомерном математическом пространстве классифицировать, аналогично методике [11], подсолнечное масло, рапсовое масло и горчичное масло. По данным, полученным при температуре $17^{\circ} \mathrm{C} \div 1^{\circ} \mathrm{C}$, не удалось построить математическую модель, позволявшую классифицировать те же виды ПРМ.

Результаты предварительного этапа исследований показали, что, влияние фрактора сезонного изменения температуры от $17^{\circ} \mathrm{C} \div 1^{\circ} \mathrm{C}$ до $22^{\circ} \mathrm{C} \div 1{ }^{\circ} \mathrm{C}$ в помещении, где происходили замеры потенциалов сенсоров в водно-спиртовых эмульсиях ПРМ, оказалось существенно большим, чем это следует из уравнения Никольского (1), описывающего отклик потенциометрических сенсоров в гомогенных водных растворах.

Для исследования электрохимических свойств эмульсий при различных температурах нами были сформированы две модельные серии, содержащие по семь образцов нерафинированного и рафинированного подсолнечного масла. Первоочередность изучения эмульсий на основе подсолнечного масла продиктована масштабом производства этого вида масла в России, превышающим производство всех других видов ПРМ почти в два раза.

Таблица 1 - Жирнокислотный состав образцов нерафинированного подсолнечного масла, (\%)

\begin{tabular}{|c|c|c|c|c|c|c|c|}
\hline $\begin{array}{c}\text { Условное } \\
\text { обозначение } \\
\text { жирных } \\
\text { кислот }\end{array}$ & $\begin{array}{c}\text { Образец } \\
\text { № 1 }\end{array}$ & $\begin{array}{c}\text { Образец } \\
\text { № 2 }\end{array}$ & $\begin{array}{c}\text { Образец } \\
\text { № 3 }\end{array}$ & $\begin{array}{c}\text { Образец } \\
\text { № 5 }\end{array}$ & $\begin{array}{c}\text { Образец } \\
\text { № 14 }\end{array}$ & $\begin{array}{c}\text { Образец } \\
\text { № 15 }\end{array}$ & $\begin{array}{c}\text { Образец } \\
\text { № 16 }\end{array}$ \\
\hline С 14:0 & - & - & & - & & 0,1 & \\
\hline C 16:0 & 6,5 & 6,2 & 6,1 & 6,0 & 6,1 & 6,2 & 6,1 \\
\hline C 16:1 & & - & - & - & & 0,1 & 0,1 \\
\hline C 18:0 & 2,3 & 2,9 & 2,5 & 3,1 & 3,0 & 3,3 & 3,0 \\
\hline C 18:1 & 28,1 & 26,4 & 27,1 & 20,8 & 18,8 & 27,0 & 28,4 \\
\hline C 18:2 & 62,5 & 64,3 & 63,6 & 69,1 & 70,1 & 61,2 & 61,2 \\
\hline C 18:3 & - & 0,1 & 0,1 & - & & 0,1 & 0,1 \\
\hline C 20:0 & 0,3 & 0,2 & 0,4 & 0,2 & 0,3 & 0,3 & 0,3 \\
\hline C 20:1 & 0,1 & & - & 0,1 & & 0,2 & 0,2 \\
\hline C 22:0 & 0,2 & 0,4 & 0,2 & 0,7 & 1,3 & 0,6 & 0,7 \\
\hline C 24:0 & & - & & - & & 0,1 & \\
\hline
\end{tabular}




\section{ИССЛЕДОВАНИЕ СВОЙСТВ ВОДНО-СПИРТОВЫХ ЭМУЛЬСИЙ ПОДСОЛНЕЧНОГО МАСЛА МУЛЬТИСЕНСОРНОЙ СИСТЕМОЙ ПРИ РАЗЛИЧНЫХ ТЕМПЕРАТУРАХ}

Таблица 2 - Жирнокислотный состав образцов рафинированного подсолнечного масла, (\%)

\begin{tabular}{|c|c|c|c|c|c|c|c|}
\hline $\begin{array}{c}\text { Условное } \\
\text { обозначение } \\
\text { жирных } \\
\text { кислот }\end{array}$ & $\begin{array}{c}\text { Образец } \\
\text { № 4 }\end{array}$ & $\begin{array}{c}\text { Образец } \\
\text { № 6 }\end{array}$ & $\begin{array}{c}\text { Образец } \\
\text { № 8 }\end{array}$ & $\begin{array}{c}\text { Образец } \\
\text { № 9 }\end{array}$ & $\begin{array}{c}\text { Образец } \\
\text { № 10 }\end{array}$ & $\begin{array}{c}\text { Образец } \\
\text { № 11 }\end{array}$ & $\begin{array}{c}\text { Образец } \\
\text { № 12 }\end{array}$ \\
\hline С 14:0 & - & - & 0,1 & - & - & & \\
\hline С 16:0 & 6,2 & 6,1 & 6,4 & 6,5 & 6,3 & 5,7 & 5,8 \\
\hline С 18:0 & 2,8 & 2,3 & 3,0 & 2,8 & 2,6 & 2,7 & 2,9 \\
\hline C 18:1 & 26,2 & 24,5 & 23,7 & 30,8 & 23,9 & 29,6 & 27,2 \\
\hline С 18:2 & 64,1 & 66,3 & 65,5 & 59,0 & 66,2 & 61,2 & 63,3 \\
\hline С 18:3 & - & 0,2 & 0,1 & - & & & \\
\hline С 20:0 & 0,2 & 0,2 & 0,3 & 0,2 & 0,2 & 0,3 & 0,2 \\
\hline С 22:0 & 0,5 & 0,4 & 0,8 & 0,7 & 0,8 & 0,5 & 0,6 \\
\hline C 24:0 & & - & 0,1 & - & & & \\
\hline
\end{tabular}

Жирнокислотный состав исследованных образцов нерафинированного подсолнечного масла приведен в таблице 1 , а рафинированного подсолнечного масла - в таблице 2.

Представленные показатели в таблицах 1 и 2 были получены в соответствии с ГОСТ Р 51486-99, ГОСТ Р 51483-99 и ГОСТ 316632012 на газо-жидкостном хроматографе «Bruker-Scion 436 GS» с использованием капиллярной колонки BR - Swax (catal. \# BR 89377) длиной 30м, диаметром 0,25 мм и активной фразой на основе полиэтиленгликоля.

Для проведения стадии кондиционирования сенсоров на модельной установке при заданных температурах, сначала готовили жиросодержащую эмульсию определённого в ходе предварительных исследований состава с использованием образцов подсолнечного масла из таблиц 1 и 2.

Кондиционирование массива из 7 электродов в водно-спиртовой эмульсии анализируемого образца ПРМ производилось в течение 10 минут. Измерения разности потенциалов происходило в автоматическом режиме через каждые 3 секунды. Данные кондиционирования не учитывались в последующих расчётах стандартного отклонения, являющегося критерием воспроизводимости откликов сенсоров массива. Затем массив поочерёдно промывался гексаном, раствором ПАВ и дистиллированной водой. После проведения стадии кондиционирования были приготовлены четыре одинаковые пробы эмульсии на основе образца подсолнечного масла, ис- пользованного при кондиционировании, для четырех параллельных измерений разности потенциалов сенсоров массива при определённой температуре. Измерение разности потенциалов каждым электродом массива в каждой из проб производилось в автоматическом режиме в течение 2-3 минут через каждые 3 секунды. Последние десять численных значений фиксировались, а затем для них вычислялись средние арифметические и стандартные отклонения значений средних арифметических параллельных проб. По этим данным затем рассчитывались суммарные значения стандартных отклонений потенциалов сенсоров всего массива и средние значения суммарных величин стандартных отклонений потенциалов сенсоров массива для всей серии образцов при определённой температуре.

После проведения измерений каждой из параллельных проб, массив электродов промывался аналогично тому, как это делалось после кондиционирования.

Разности потенциалов между электродом сравнения и электродами массива в эмульсиях образцов нерафинированного и рафинированного подсолнечного масла измерялись при температурах: $17{ }^{\circ} \mathrm{C} \pm 1^{\circ} \mathrm{C}$; $22^{\circ} \mathrm{C} \pm 1{ }^{\circ} \mathrm{C} ; 26^{\circ} \mathrm{C} \pm 1^{\circ} \mathrm{C}$ и $32^{\circ} \mathrm{C} \pm 1^{\circ} \mathrm{C}$.

Экспериментальные и расчётные данные для образцов нерафинированного подсолнечного масла представлены в таблицах $3 \div 6$, а для образцов рафинированного подсолнечного масла в таблицах $7 \div 10$. 
А. В. ФЁДОРОВ, Д. О. КИРСАНОВ, А. В. ЛЕГИН, И. А. ЛИСИЦЫНА, С. М. ВОЛКОВ, А. Г. НОВОСЁЛОВ, Ю. А. ПОЗДЕЕВА, Е. А. ЕЛОВЕГИНА

Таблица 3 - Среднеарифметические значения потенциалов сенсоров параллельных проб (мВ), стандартные отклонения сенсоров, суммарное стандартное отклонение сенсоров, средние значения суммарных стандартных отклонений потенциалов сенсоров массива для образцов нерафинированных подсолнечных масел при $\mathrm{t}=17^{\circ} \mathrm{C} \pm 1^{\circ} \mathrm{C}$

\begin{tabular}{|c|c|c|c|c|c|c|c|c|c|c|}
\hline \multirow{2}{*}{$\begin{array}{l}\text { Образцы } \\
\text { ПРМ }\end{array}$} & \multirow{2}{*}{ Показатель } & \multicolumn{7}{|c|}{ Номер сенсора } & \multirow{2}{*}{ Сумма } & \multirow{2}{*}{$\begin{array}{c}\text { Среднее } \\
\text { значение } \\
\text { сумм }\end{array}$} \\
\hline & & 1 & 2 & 3 & 4 & 5 & 6 & 7 & & \\
\hline \multirow[b]{2}{*}{ Образец № 1} & Потенциал, мВ & 206 & 174 & 127 & -253 & 98 & -358 & 221 & & \multirow{14}{*}{103} \\
\hline & $\begin{array}{l}\text { Стандартное } \\
\text { отклонение }\end{array}$ & 7 & 3 & 3 & 5 & 1 & 21 & 59 & 100 & \\
\hline \multirow[b]{2}{*}{ Образец № 2} & Потенциал, мВ & 219 & 188 & 146 & -262 & 118 & -375 & 213 & & \\
\hline & $\begin{array}{c}\text { Стандартное } \\
\text { отклонение }\end{array}$ & 15 & 16 & 17 & 17 & 16 & 7 & 14 & 102 & \\
\hline \multirow[b]{2}{*}{ Образец № 3} & Потенциал, мВ & 173 & 134 & 101 & -261 & 101 & -389 & 204 & & \\
\hline & $\begin{array}{l}\text { Стандартное } \\
\text { отклонение }\end{array}$ & 47 & 50 & 36 & 18 & 30 & 11 & 21 & 213 & \\
\hline \multirow[b]{2}{*}{ Образец № 5} & Потенциал, мВ & 195 & 166 & 140 & -285 & 97 & -384 & 198 & & \\
\hline & $\begin{array}{c}\text { Стандартное } \\
\text { отклонение }\end{array}$ & 5 & 2 & 12 & 5 & 8 & 30 & 7 & 67 & \\
\hline \multirow[b]{2}{*}{ Образец № 14} & Потенциал, мВ & 186 & 146 & 91 & -306 & 40 & -390 & 172 & & \\
\hline & $\begin{array}{l}\text { Стандартное } \\
\text { отклонение }\end{array}$ & 12 & 15 & 13 & 7 & 15 & 31 & 13 & 105 & \\
\hline \multirow[b]{2}{*}{ Образец № 15} & Потенциал, мВ & 200 & 179 & 114 & -284 & 83 & -402 & 222 & & \\
\hline & $\begin{array}{l}\text { Стандартное } \\
\text { отклонение }\end{array}$ & 2 & 6 & 4 & 4 & 8 & 6 & 13 & 43 & \\
\hline \multirow[b]{2}{*}{ Образец № 16} & Потенциал, мВ & 245 & 198 & 129 & -262 & 90 & -387 & 272 & & \\
\hline & $\begin{array}{l}\text { Стандартное } \\
\text { отклонение }\end{array}$ & 8 & 8 & 6 & 8 & 19 & 1 & 39 & 89 & \\
\hline
\end{tabular}

Таблица 4 - Среднеарифрметические значения потенциалов сенсоров параллельных проб (мB), их стандартные отклонения, суммарное стандартное отклонение сенсоров, средние значения суммарных стандартных отклонений потенциалов сенсоров массива для образцов нерафинированных подсолнечных масел при $\mathrm{t}=22 \pm 1^{\circ} \mathrm{C}$

\begin{tabular}{|c|c|c|c|c|c|c|c|c|c|c|}
\hline \multirow{2}{*}{ Образцы ПРМ } & \multirow{2}{*}{ Показатель } & \multicolumn{7}{|c|}{ Номер сенсора } & \multirow{2}{*}{$\begin{array}{l}\text { Сум- } \\
\text { ма }\end{array}$} & \multirow{2}{*}{$\begin{array}{c}\text { Среднее } \\
\text { значение } \\
\text { сумм }\end{array}$} \\
\hline & & 1 & 2 & 3 & 4 & 5 & 6 & 7 & & \\
\hline \multirow[b]{2}{*}{ Образец № 1} & Потенциал, мВ & 244 & 201 & 134 & -244 & 125 & 138 & 50 & & \multirow{14}{*}{92} \\
\hline & $\begin{array}{l}\text { Стандартное } \\
\text { отклонение }\end{array}$ & 4 & 11 & 15 & 4 & 7 & 77 & 40 & 157 & \\
\hline \multirow[b]{2}{*}{ Образец № 2} & Потенциал, мВ & 246 & 204 & 163 & -257 & 131 & -58 & 226 & & \\
\hline & $\begin{array}{c}\text { Стандартное } \\
\text { отклонение }\end{array}$ & 3 & 3 & 4 & 6 & 5 & 132 & 5 & 158 & \\
\hline \multirow[b]{2}{*}{ Образец № 3} & Потенциал, мВ & 244 & 203 & 148 & -272 & 119 & 25 & 235 & & \\
\hline & $\begin{array}{l}\text { Стандартное } \\
\text { отклонение }\end{array}$ & 8 & 6 & 0 & 4 & 4 & 121 & 5 & 149 & \\
\hline \multirow[b]{2}{*}{ Образец № 5} & Потенциал, мВ & 240 & 199 & 59 & -284 & 38 & -393 & 224 & & \\
\hline & $\begin{array}{l}\text { Стандартное } \\
\text { отклонение }\end{array}$ & 13 & 23 & 26 & 4 & 24 & 6 & 2 & 99 & \\
\hline \multirow[b]{2}{*}{ Образец № 14} & Потенциал, мВ & 246 & 221 & 146 & -276 & 135 & -377 & 257 & & \\
\hline & $\begin{array}{l}\text { Стандартное } \\
\text { отклонение }\end{array}$ & 3 & 4 & 6 & 1 & 3 & 5 & 2 & 24 & \\
\hline \multirow[b]{2}{*}{ Образец № 15} & Потенциал, мВ & 243 & 212 & 121 & -265 & 134 & -381 & 213 & & \\
\hline & $\begin{array}{l}\text { Стандартное } \\
\text { отклонение }\end{array}$ & 2 & 4 & 9 & 1 & 6 & 3 & 7 & 32 & \\
\hline \multirow[b]{2}{*}{ Образец № 16} & Потенциал, мВ & 254 & 222 & 87 & -264 & 98 & -386 & 232 & & \\
\hline & $\begin{array}{l}\text { Стандартное } \\
\text { отклонение }\end{array}$ & 4 & 3 & 8 & 2 & 5 & 3 & 3 & 27 & \\
\hline
\end{tabular}




\section{ИССЛЕДОВАНИЕ СВОЙСТВ ВОДНО-СПИРТОВЫХ ЭМУЛЬСИЙ ПОДСОЛНЕЧНОГО МАСЛА МУЛЬТИСЕНСОРНОЙ СИСТЕМОЙ ПРИ РАЗЛИЧНЫХ ТЕМПЕРАТУРАХ}

Таблица 5 - Среднеарифрметические значения потенциалов сенсоров параллельных проб (мB), их стандартные отклонения, суммарное стандартное отклонение сенсоров, средние значения суммарных стандартных отклонений потенциалов сенсоров массива для образцов нерафринированных подсолнечных масел при $\mathrm{t}=26 \pm 1^{\circ} \mathrm{C}$

\begin{tabular}{|c|c|c|c|c|c|c|c|c|c|c|}
\hline \multirow{2}{*}{ Образцы ПРМ } & \multirow{2}{*}{ Показатель } & \multicolumn{7}{|c|}{ Номер сенсора } & \multirow{2}{*}{$\begin{array}{l}\text { Сум- } \\
\text { ма }\end{array}$} & \multirow{2}{*}{$\begin{array}{c}\text { Среднее } \\
\text { значение } \\
\text { сумм }\end{array}$} \\
\hline & & 1 & 2 & 3 & 4 & 5 & 6 & 7 & & \\
\hline \multirow[b]{2}{*}{ Образец № 1} & Потенциал, мВ & 237 & 212 & 140 & -277 & 116 & -390 & 118 & - & \multirow{14}{*}{38} \\
\hline & $\begin{array}{l}\text { Стандартное } \\
\text { отклонение }\end{array}$ & 4 & 1 & 7 & 1 & 3 & 10 & 22 & 49 & \\
\hline \multirow[b]{2}{*}{ Образец № 2} & Потенциал, мВ & 238 & 216 & 130 & -274 & 122 & -405 & 266 & - & \\
\hline & $\begin{array}{l}\text { Стандартное } \\
\text { отклонение }\end{array}$ & 6 & 3 & 8 & 3 & 4 & 11 & 1 & 35 & \\
\hline \multirow[b]{2}{*}{ Образец № 3} & Потенциал, мВ & 232 & 206 & 146 & -265 & 133 & -342 & 215 & - & \\
\hline & $\begin{array}{l}\text { Стандартное } \\
\text { отклонение }\end{array}$ & 6 & 5 & 6 & 6 & 10 & 3 & 26 & 61 & \\
\hline \multirow[b]{2}{*}{ Образец № 5} & Потенциал, мВ & 236 & 200 & 117 & -278 & 138 & -388 & 250 & - & \\
\hline & $\begin{array}{c}\text { Стандартное } \\
\text { отклонение }\end{array}$ & 5 & 2 & 5 & 6 & 6 & 7 & 7 & 38 & \\
\hline \multirow[b]{2}{*}{ Образец № 14} & Потенциал, мВ & 246 & 221 & 146 & -276 & 135 & -377 & 257 & - & \\
\hline & $\begin{array}{c}\text { Стандартное } \\
\text { отклонение }\end{array}$ & 3 & 4 & 6 & 1 & 3 & 5 & 2 & 24 & \\
\hline \multirow[b]{2}{*}{ Образец № 15} & Потенциал, мВ & 231 & 212 & 161 & -259 & 146 & -377 & 258 & - & \\
\hline & $\begin{array}{l}\text { Стандартное } \\
\text { отклонение }\end{array}$ & 5 & 3 & 13 & 2 & 4 & 5 & 4 & 36 & \\
\hline \multirow[b]{2}{*}{ Образец № 16} & Потенциал, мВ & 250 & 224 & 150 & -261 & 133 & -364 & 267 & - & \\
\hline & $\begin{array}{l}\text { Стандартное } \\
\text { отклонение }\end{array}$ & 3 & 1 & 4 & 2 & 2 & 11 & 1 & 24 & \\
\hline
\end{tabular}

Таблица 6 - Среднеарифметические значения потенциалов сенсоров параллельных проб (мB), их стандартные отклонения, суммарное стандартное отклонение сенсоров, средние значения суммарных стандартных отклонений потенциалов сенсоров массива для образцов нерафринированных подсолнечных масел при $\mathrm{t}=32 \pm 1^{\circ} \mathrm{C}$

\begin{tabular}{|c|c|c|c|c|c|c|c|c|c|c|}
\hline \multirow{2}{*}{ Образцы ПРМ } & \multirow{2}{*}{ Показатель } & \multicolumn{7}{|c|}{ Номер электрода } & \multirow{2}{*}{$\begin{array}{c}\text { Сум- } \\
\text { ма }\end{array}$} & \multirow{2}{*}{$\begin{array}{c}\text { Среднее } \\
\text { значение } \\
\text { сумм }\end{array}$} \\
\hline & & 1 & 2 & 3 & 4 & 5 & 6 & 7 & & \\
\hline \multirow[b]{2}{*}{ Образец № 1} & Потенциал, мВ & 230 & 212 & 144 & -277 & 110 & -337 & 70 & & \multirow{14}{*}{30} \\
\hline & $\begin{array}{c}\text { Стандартное } \\
\text { отклонение }\end{array}$ & 8 & 4 & 5 & 4 & 8 & 13 & 11 & 54 & \\
\hline \multirow[b]{2}{*}{ Образец № 2} & Потенциал, мВ & 239 & 212 & 143 & -276 & 126 & -357 & 260 & & \\
\hline & $\begin{array}{c}\text { Стандартное } \\
\text { отклонение }\end{array}$ & 13 & 2 & 1 & 2 & 1 & 14 & 1 & 34 & \\
\hline \multirow[b]{2}{*}{ Образец № 3} & Потенциал, мB & 231 & 201 & 129 & -278 & 143 & -377 & 266 & & \\
\hline & $\begin{array}{c}\text { Стандартное } \\
\text { отклонение }\end{array}$ & 2 & 2 & 3 & 1 & 3 & 4 & 2 & 18 & \\
\hline \multirow[b]{2}{*}{ Образец № 5} & Потенциал, мВ & 240 & 215 & 162 & -282 & 140 & -345 & 267 & & \\
\hline & $\begin{array}{c}\text { Стандартное } \\
\text { отклонение }\end{array}$ & 4 & 4 & 11 & 1 & 4 & 11 & 3 & 38 & \\
\hline \multirow[b]{2}{*}{ Образец № 14} & Потенциал, мB & 250 & 220 & 151 & -287 & 133 & -392 & 251 & & \\
\hline & $\begin{array}{c}\text { Стандартное } \\
\text { отклонение }\end{array}$ & 2 & 2 & 2 & 2 & 1 & 13 & 1 & 23 & \\
\hline \multirow[b]{2}{*}{ Образец № 15} & Потенциал, мВ & 255 & 226 & 166 & -270 & 143 & -351 & 268 & & \\
\hline & $\begin{array}{c}\text { Стандартное } \\
\text { отклонение }\end{array}$ & 3 & 3 & 5 & 1 & 3 & 12 & 1 & 29 & \\
\hline \multirow[b]{2}{*}{ Образец № 16} & Потенциал, мВ & 251 & 227 & 166 & -270 & 137 & -375 & 264 & & \\
\hline & $\begin{array}{c}\text { Стандартное } \\
\text { отклонение }\end{array}$ & 2 & 1 & 2 & 1 & 3 & 5 & 2 & 16 & \\
\hline
\end{tabular}


А. В. ФЁДОРОВ, Д. О. КИРСАНОВ, А. В. ЛЕГИН, И. А. ЛИСИЦЫНА, С. М. ВОЛКОВ, А. Г. НОВОСЁЛОВ, Ю. А. ПОЗДЕЕВА, Е. А. ЕЛОВЕГИНА

Таблица 7 - Среднеарифметические значения потенциалов сенсоров параллельных проб (мВ), их стандартные отклонения, суммарное стандартное отклонение сенсоров, средние значения суммарных стандартных отклонений потенциалов сенсоров массива для образцов рафинированных подсолнечных масел при $\mathrm{t}=17 \pm 1^{\circ} \mathrm{C}$

\begin{tabular}{|c|c|c|c|c|c|c|c|c|c|c|}
\hline \multirow{2}{*}{ Образцы ПРМ } & \multirow{2}{*}{ Показатель } & \multicolumn{7}{|c|}{ Номер сенсора } & \multirow{2}{*}{$\begin{array}{l}\text { Сум- } \\
\text { ма }\end{array}$} & \multirow{2}{*}{$\begin{array}{c}\text { Среднее } \\
\text { значение } \\
\text { сумм }\end{array}$} \\
\hline & & 1 & 2 & 3 & 4 & 5 & 6 & 7 & & \\
\hline \multirow[b]{2}{*}{ Образец № 4} & Потенциал, мB & 228 & 195 & 151 & -275 & 118 & -406 & 212 & & \multirow{14}{*}{75} \\
\hline & $\begin{array}{l}\text { Стандартное } \\
\text { отклонение }\end{array}$ & 12 & 5 & 4 & 2 & 8 & 10 & 5 & 45 & \\
\hline \multirow[b]{2}{*}{ Образец № 6} & Потенциал, мВ & 187 & 160 & 104 & -289 & 61 & -365 & 150 & & \\
\hline & $\begin{array}{l}\text { Стандартное } \\
\text { отклонение }\end{array}$ & 4 & 2 & 13 & 20 & 4 & 48 & 48 & 138 & \\
\hline \multirow[b]{2}{*}{ Образец № 8} & Потенциал, мВ & 207 & 195 & 138 & -281 & 108 & -411 & 239 & & \\
\hline & $\begin{array}{l}\text { Стандартное } \\
\text { отклонение }\end{array}$ & 7 & 3 & 3 & 1 & 7 & 7 & 8 & 37 & \\
\hline \multirow[b]{2}{*}{ Образец № 9} & Потенциал, мВ & 207 & 185 & 135 & -299 & 99 & -410 & 204 & & \\
\hline & $\begin{array}{c}\text { Стандартное } \\
\text { отклонение }\end{array}$ & 6 & 6 & 10 & 9 & 17 & 18 & 17 & 83 & \\
\hline \multirow[b]{2}{*}{ Образец № 10} & Потенциал, мB & 199 & 160 & 105 & -329 & 40 & -467 & 182 & & \\
\hline & $\begin{array}{l}\text { Стандартное } \\
\text { отклонение }\end{array}$ & 13 & 10 & 9 & 13 & 9 & 16 & 29 & 99 & \\
\hline \multirow[b]{2}{*}{ Образец № 11} & Потенциал, мВ & 230 & 202 & 133 & -283 & 95 & -418 & 228 & & \\
\hline & $\begin{array}{l}\text { Стандартное } \\
\text { отклонение }\end{array}$ & 4 & 1 & 3 & 2 & 3 & 4 & 4 & 21 & \\
\hline \multirow[b]{2}{*}{ Образец № 12} & Потенциал, мВ & 180 & 149 & 90 & -315 & 40 & -393 & 171 & & \\
\hline & $\begin{array}{c}\text { Стандартное } \\
\text { отклонение }\end{array}$ & 7 & 2 & 7 & 21 & 8 & 30 & 29 & 108 & \\
\hline
\end{tabular}

Таблица 8 - Среднеарифрметические значения потенциалов сенсоров параллельных проб (мB), их стандартные отклонения, суммарное стандартное отклонение сенсоров, средние значения суммарных стандартных отклонений потенциалов сенсоров массива для образцов рафинированных подсолнечных масел при $\mathrm{t}=22 \pm 1^{\circ} \mathrm{C}$

\begin{tabular}{|c|c|c|c|c|c|c|c|c|c|c|}
\hline \multirow[b]{2}{*}{ Образцы ПРМ } & \multirow[b]{2}{*}{ Показатель } & \multicolumn{7}{|c|}{ Номер сенсора } & \multirow{2}{*}{$\begin{array}{c}\text { Сум- } \\
\text { ма }\end{array}$} & \multirow{2}{*}{$\begin{array}{c}\text { Среднее } \\
\text { значение } \\
\text { сумм }\end{array}$} \\
\hline & & 1 & 2 & 3 & 4 & 5 & 6 & 7 & & \\
\hline \multirow[b]{2}{*}{ Образец № 4} & Потенциал, мВ & 237 & 195 & 121 & -281 & 118 & -382 & 194 & & \multirow{14}{*}{52} \\
\hline & $\begin{array}{c}\text { Стандартное } \\
\text { отклонение }\end{array}$ & 7 & 6 & 4 & 20 & 8 & 19 & 7 & 71 & \\
\hline \multirow[b]{2}{*}{ Образец № 6} & Потенциал, мВ & 228 & 203 & 132 & -297 & 114 & -384 & 193 & & \\
\hline & $\begin{array}{c}\text { Стандартное } \\
\text { отклонение }\end{array}$ & 1 & 1 & 3 & 8 & 17 & 6 & 4 & 40 & \\
\hline \multirow[b]{2}{*}{ Образец № 8} & Потенциал, мВ & 226 & 188 & 94 & -300 & 107 & -404 & 194 & & \\
\hline & $\begin{array}{c}\text { Стандартное } \\
\text { отклонение }\end{array}$ & 4 & 1 & 20 & 5 & 22 & 17 & 7 & 76 & \\
\hline \multirow[b]{2}{*}{ Образец № 9} & Потенциал, мВ & 231 & 196 & 60 & -307 & 84 & -432 & 203 & & \\
\hline & $\begin{array}{c}\text { Стандартное } \\
\text { отклонение }\end{array}$ & 2 & 5 & 12 & 4 & 9 & 6 & 6 & 46 & \\
\hline \multirow[b]{2}{*}{ Образец № 10} & Потенциал, мВ & 236 & 204 & 59 & -312 & 30 & -447 & 211 & & \\
\hline & $\begin{array}{c}\text { Стандартное } \\
\text { отклонение }\end{array}$ & 3 & 1 & 17 & 3 & 27 & 2 & 3 & 57 & \\
\hline \multirow[b]{2}{*}{ Образец № 11} & Потенциал, мВ & 241 & 205 & 42 & -315 & -24 & -455 & 222 & & \\
\hline & $\begin{array}{c}\text { Стандартное } \\
\text { отклонение }\end{array}$ & 4 & 3 & 6 & 1 & 13 & 4 & 5 & 36 & \\
\hline \multirow[b]{2}{*}{ Образец № 12} & Потенциал, мВ & 240 & 222 & 158 & -290 & 138 & -376 & 249 & & \\
\hline & $\begin{array}{c}\text { Стандартное } \\
\text { отклонение }\end{array}$ & 2 & 3 & 9 & 2 & 5 & 12 & 1 & 35 & \\
\hline
\end{tabular}




\section{ИССЛЕДОВАНИЕ СВОЙСТВ ВОДНО-СПИРТОВЫХ ЭМУЛЬСИЙ ПОДСОЛНЕЧНОГО МАСЛА МУЛЬТИСЕНСОРНОЙ СИСТЕМОЙ ПРИ РАЗЛИЧНЫХ ТЕМПЕРАТУРАХ}

Таблица 9 - Среднеарифметические значения потенциалов сенсоров параллельных проб (мB), их стандартные отклонения, суммарное стандартное отклонение сенсоров, средние значения суммарных стандартных отклонений потенциалов сенсоров массива для образцов рафинированных подсолнечных масел при $\mathrm{t}=26 \pm 1^{\circ} \mathrm{C}$

\begin{tabular}{|c|c|c|c|c|c|c|c|c|c|c|}
\hline \multirow{2}{*}{ Образцы ПРМ } & \multirow{2}{*}{ Показатель } & \multicolumn{7}{|c|}{ Номер сенсора } & \multirow[t]{2}{*}{$\begin{array}{l}\text { Сум- } \\
\text { ма }\end{array}$} & \multirow{2}{*}{$\begin{array}{c}\text { Среднее } \\
\text { значение } \\
\text { сумм }\end{array}$} \\
\hline & & 1 & 2 & 3 & 4 & 5 & 6 & 7 & & \\
\hline \multirow{2}{*}{ Образец № 4} & Потенциал, мВ & 232 & 212 & 132 & -280 & 134 & -365 & 243 & & \multirow{14}{*}{41} \\
\hline & $\begin{array}{c}\text { Стандартное } \\
\text { отклонение }\end{array}$ & 3 & 4 & 11 & 5 & 4 & 18 & 4 & 49 & \\
\hline \multirow[b]{2}{*}{ Образец № 6} & Потенциал, мВ & 229 & 197 & 146 & -289 & 118 & -328 & 181 & & \\
\hline & $\begin{array}{l}\text { Стандартное } \\
\text { отклонение }\end{array}$ & 5 & 3 & 8 & 4 & 7 & 24 & 26 & 77 & \\
\hline \multirow[b]{2}{*}{ Образец № 8} & Потенциал, мВ & 235 & 195 & 102 & -295 & 121 & -412 & 235 & & \\
\hline & $\begin{array}{l}\text { Стандартное } \\
\text { отклонение }\end{array}$ & 6 & 6 & 3 & 6 & 3 & 10 & 4 & 39 & \\
\hline \multirow[b]{2}{*}{ Образец № 9} & Потенциал, мВ & 240 & 211 & 142 & -271 & 147 & -377 & 255 & & \\
\hline & $\begin{array}{c}\text { Стандартное } \\
\text { отклонение }\end{array}$ & 9 & 4 & 4 & 8 & 2 & 7 & 5 & 38 & \\
\hline \multirow[b]{2}{*}{ Образец № 10} & Потенциал, мВ & 241 & 209 & 131 & -284 & 118 & -345 & 253 & & \\
\hline & $\begin{array}{c}\text { Стандартное } \\
\text { отклонение }\end{array}$ & 1 & 1 & 3 & 2 & 5 & 4 & 4 & 21 & \\
\hline \multirow[b]{2}{*}{ Образец № 11} & Потенциал, мВ & 247 & 219 & 153 & -281 & 134 & -352 & 251 & & \\
\hline & $\begin{array}{l}\text { Стандартное } \\
\text { отклонение }\end{array}$ & 4 & 4 & 3 & 3 & 5 & 4 & 3 & 27 & \\
\hline \multirow[b]{2}{*}{ Образец № 12} & Потенциал, мВ & 232 & 200 & 112 & -294 & 120 & -395 & 235 & & \\
\hline & $\begin{array}{c}\text { Стандартное } \\
\text { отклонение }\end{array}$ & 4 & 4 & 9 & 1 & 4 & 12 & 4 & 37 & \\
\hline
\end{tabular}

Таблица 10 - Среднеарифметические значения потенциалов сенсоров параллельных проб (мВ), их стандартные отклонения, суммарное стандартное отклонение сенсоров, средние значения суммарных стандартных отклонений потенциалов сенсоров массива для образцов рафинированных подсолнечных масел при $\mathrm{t}=32 \pm 1^{\circ} \mathrm{C}$

\begin{tabular}{|c|c|c|c|c|c|c|c|c|c|c|}
\hline \multirow[b]{2}{*}{ Образцы ПРМ } & \multirow[b]{2}{*}{ Показатель } & \multicolumn{7}{|c|}{ Номер сенсора } & \multirow{2}{*}{$\begin{array}{l}\text { Сум } \\
\text { ма }\end{array}$} & \multirow{2}{*}{$\begin{array}{c}\text { Среднее } \\
\text { значение } \\
\text { сумм }\end{array}$} \\
\hline & & 1 & 2 & 3 & 4 & 5 & 6 & 7 & & \\
\hline \multirow[b]{2}{*}{ Образец № 4} & Потенциал, мВ & 230 & 200 & 98 & -302 & 111 & -424 & 245 & & \multirow{14}{*}{25} \\
\hline & $\begin{array}{l}\text { Стандартное } \\
\text { отклонение }\end{array}$ & 3 & 4 & 6 & 1 & 3 & 2 & 5 & 25 & \\
\hline \multirow[b]{2}{*}{ Образец № 6} & Потенциал, мВ & 235 & 215 & 135 & -304 & 116 & -411 & 252 & & \\
\hline & $\begin{array}{c}\text { Стандартное } \\
\text { отклонение }\end{array}$ & 5 & 2 & 2 & 3 & 3 & 3 & 2 & 19 & \\
\hline \multirow[b]{2}{*}{ Образец № 8} & Потенциал, мВ & 235 & 220 & 146 & -300 & 133 & -384 & 260 & & \\
\hline & $\begin{array}{l}\text { Стандартное } \\
\text { отклонение }\end{array}$ & 1 & 4 & 8 & 3 & 4 & 9 & 4 & 32 & \\
\hline \multirow[b]{2}{*}{ Образец № 9} & Потенциал, мВ & 246 & 220 & 160 & -293 & 140 & -357 & 260 & & \\
\hline & $\begin{array}{l}\text { Стандартное } \\
\text { отклонение }\end{array}$ & 6 & 2 & 2 & 3 & 1 & 7 & 5 & 25 & \\
\hline \multirow[b]{2}{*}{ Образец № 10} & Потенциал, мВ & 243 & 221 & 145 & -294 & 109 & -406 & 252 & & \\
\hline & $\begin{array}{l}\text { Стандартное } \\
\text { отклонение }\end{array}$ & 1 & 2 & 4 & 3 & 2 & 5 & 2 & 18 & \\
\hline \multirow[b]{2}{*}{ Образец № 11} & Потенциал, мВ & 248 & 218 & 152 & -282 & 132 & -357 & 252 & & \\
\hline & $\begin{array}{c}\text { Стандартное } \\
\text { отклонение }\end{array}$ & 4 & 4 & 3 & 3 & 4 & 4 & 4 & 27 & \\
\hline \multirow[b]{2}{*}{ Образец № 12} & Потенциал, мВ & 241 & 221 & 157 & -291 & 139 & -374 & 243 & & \\
\hline & $\begin{array}{c}\text { Стандартное } \\
\text { отклонение }\end{array}$ & 2 & 3 & 8 & 2 & 5 & 10 & 1 & 31 & \\
\hline
\end{tabular}


А. В. ФЁДОРОВ, Д. О. КИРСАНОВ, А. В. ЛЕГИН, И. А. ЛИСИЦЫНА, С. М. ВОЛКОВ, А. Г. НОВОСЁЛОВ, Ю. А. ПОЗДЕЕВА, Е. А. ЕЛОВЕГИНА

Зависимости суммарных значений стандартных отклонений потенциалов сенсоров массива от температуры электрохимической ячейки для образцов нерафинированного и рафинированного подсолнечного масла, полученные по данным таблиц 3-10, представлены на рисунках 1 и 2 соответственно.

Зависимости средних значения суммарных стандартных отклонений потенциалов сенсоров массива для образцов нерафинированных подсолнечных масел и рафинированных подсолнечных масел от температуры, полученные по данным таблиц $3 \div 10$ и рисунков 1 и 2, представлены на рисунке 3 .

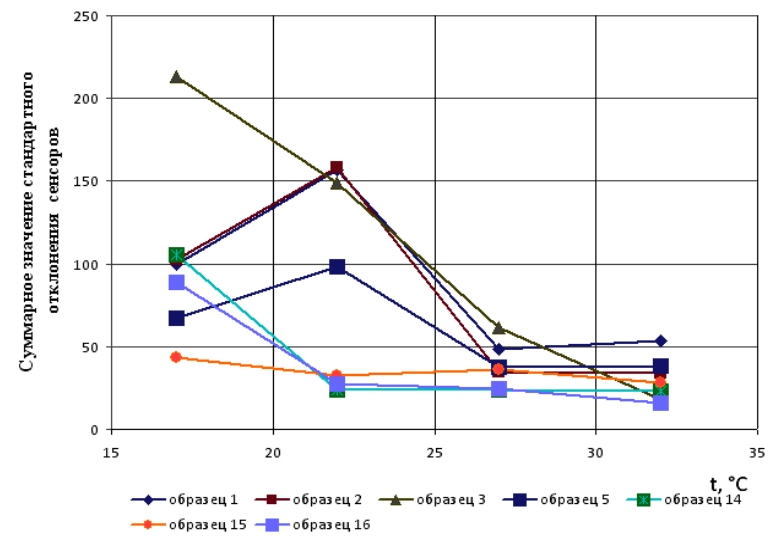

Рисунок 1 - Зависимость суммарного значения стандартного отклонения потенциалов сенсоров массива от температуры для образцов нерафинированного подсолнечного масла

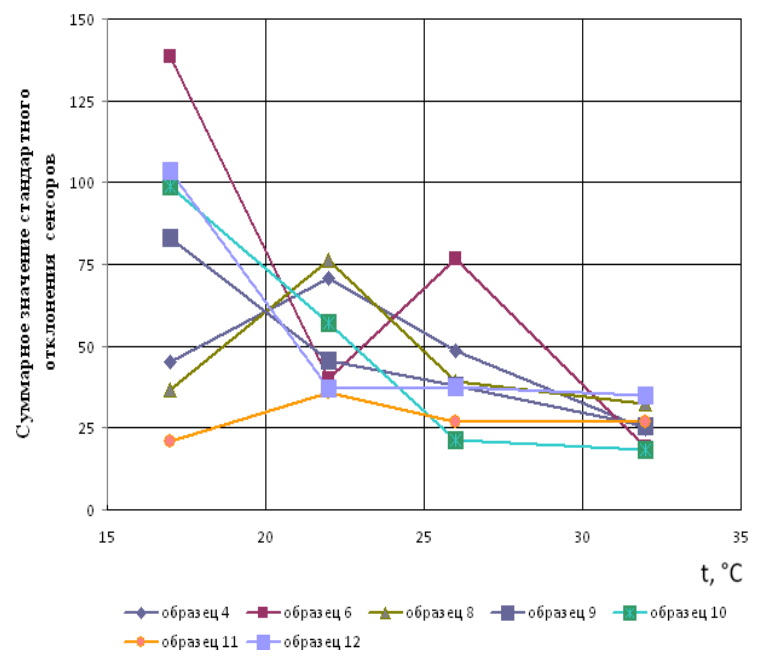

Рисунок 2 - Зависимость суммарного значения стандартного отклонения потенциалов сенсоров массива от температуры для образцов рафинированного подсолнечного масла

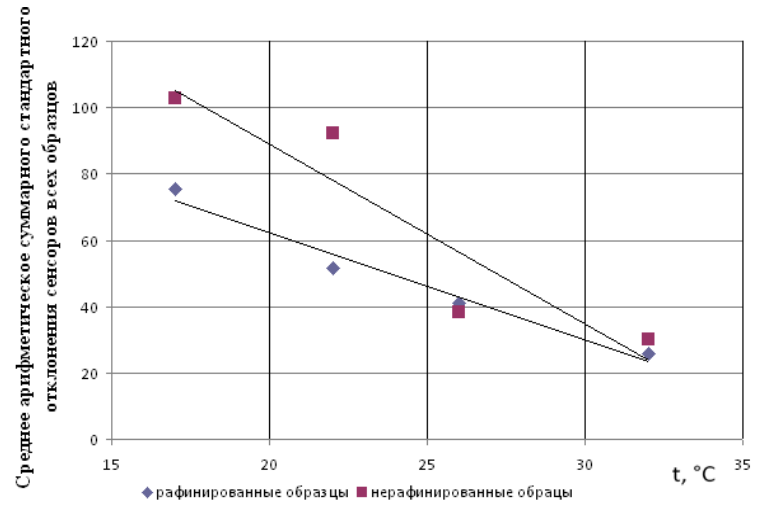

Рисунок 3 - Зависимость среднего арифметического суммарных стандартных отклонений массива сенсоров от температуры для серий образцов нерафинированного и рафинированного подсолнечных масел

Изменение численных значений среднего арифрметического суммарного стандартного отклонения массива сенсоров от температуры для серии образцов нерафинированного подсолнечного масла на рисунке 3 аппроксимируется линейной функцией:

$$
y=-5,4 t+196,9
$$

Та же зависимость для серии образцов рафиинированного подсолнечного масла на рисунке 3 аппроксимируется линейной функцией:

$$
y=-3,2 t+126,6 \text {. }
$$

Обсуждение результатов.

Состав образцов нерафринированного растительного масла, произведенных прессованием масличных семян, отличается от состава образцов рафинированного растительного масла, полученных из нерафинированного или экстракционного растительных масел по технологии рафринирования $[1,19]$. Из обрабатываемых на стадии рафринирования растительных масел удаляются некоторые компоненты, такие как свободные жирных кислоты, фросфатиды, омыляемые компоненты, воска и воскоподобные вещества, суммарное количество которых составляет до $10 \%[1,19,20]$.

С учётом высокой чувствительности мультисенсорной потенциометрии эти отличия в составах нерафинированных и рафринированных растительных масел одного вида должно существенным образом влиять на результаты измерений разности потенциалов мультисенсорной системой в водно-спиртовых эмульсиях, приготовленных на основе таких образцов. Следует отметить, что повышение воспроизводимости результатов измерений определяет эффрективность калибровок мультисенсорной системы по возможным аналитам, которые устанавливаются на следующем этапе исследований. 


\section{ИССЛЕДОВАНИЕ СВОЙСТВ ВОДНО-СПИРТОВЫХ ЭМУЛЬСИЙ ПОДСОЛНЕЧНОГО МАСЛА МУЛЬТИСЕНСОРНОЙ СИСТЕМОЙ ПРИ РАЗЛИЧНЫХ ТЕМПЕРАТУРАХ}

Данные рисунков 1 и 2, полученные из таблиц $3 \div 10$, отражают сложный характер изменения критерия воспроизводимости показаний массива - суммарного стандартного отклонения сенсоров массива - при изменении температуры для каждого образца из серий нерафинированного или рафинированного подсолнечного масла. Как видно из таблиц 1 и 2, исследованные образцы ПРМ имеют приблизительно одинаковые жирнокислотные составы, относительная разница которых несоизмерима с отличиями величин разности потенциалов и относительной разницей численных значений суммарного стандартного отклонения сенсоров массива для одинаковых образцов при различных температурах, представленные в таблицах 3-10. Причём характер зависимостей для образцов в каждой отдельной серии имеет свои особенности. Эти особенности в изменении разности потенциалов и стандартного отклонения от температуры для каждого образца. Они могут быть вызваны наличием в составе ПРМ ряда, компонентов, не входящих в жировую фрракцию, концентрация которых зависит не только от технологии получения ПРМ, но и от вида и сорта масла, а также от сорта семян и места произрастания масличного сырья. Это, несомненно, должно различным образом будет сказываться на показаниях определённых сенсоров массива в процессе исследования жиросодержащих эмульсий ПРМ при различных температурах. Однако такого рода воздействия требуют дополнительных исследований, выходящих за рамки данной работы.

Таким образом, данные таблиц 3-10 и рисунков 1 и 2 подтверждают индивидуальность отклика каждого сенсора массива на индивидуальный состав каждого из образцов при различных температурах. При этом сравнение данных, приведенных на рисунке 1 с данными рисунка 2 не позволяет количественным образом оценить отличие воспроизводимости в серии образцов нерафинированного подсолнечного масла от того же параметра в серии образцов рафинированного подсолнечного масла.

Введение дополнительного критерия воспроизводимости - среднего арифметического суммарного стандартного отклонения массива сенсоров - учитывающего специфические особенности каждой из исследуемой серии подсолнечного масла, нерафинированного и рафиинированного, позволило получить зависимости численных значений этого критерия от температуры для образцов этих масел, образующие два числовых подпространства, которые аппроксимируются различными линейными функциями, уравнения 2 и 3.
Представленные на рисунке 3 данные на примере подсолнечного масла подтверждают предположение, что компоненты растительного масла, не входящие в его жировую фракцию и удаляемые на стадии рафинирования, несмотря на их относительно малую концентрацию в масле по сравнению с концентрацией жировой фрракции, существенно влияют на характер измерений мультисенсорной системой. Однако результаты исследований, представленные на рисунке 3, позволяют получить ещё более важную информацию, влияющую на эффективность оптимизации условий калибровок мультисенсорной системы и имеющую ключевое значение для разработки методики совмещённого анализа нормируемых показателей качества ПРМ.

Как видно из уравнений (2) и (3), численные значения среднего арифметического суммарного стандартного отклонения массива сенсоров для рафинированного подсолнечного масла в интервале от $17^{\circ} \mathrm{C} \pm 1^{\circ} \mathrm{C}$ до $26^{\circ} \mathrm{C} \pm 1^{\circ} \mathrm{C}$ лежат ниже таких же значений для нерафинированного подсолнечного масла, а при температуре, близкой к $32^{\circ} \mathrm{C} \pm 1^{\circ} \mathrm{C}$, обе функции пересекаются. Т. е. воспроизводимость для серии образцов рафинированного подсолнечного масла в интервале от $17^{\circ} \mathrm{C} \pm 1^{\circ} \mathrm{C}$ до $26^{\circ} \mathrm{C} \pm 1^{\circ} \mathrm{C}$ существенно выше, чем воспроизводимость для серии образцов нерафинированного подсолнечного масла при тех же температурах. Причём воспроизводимость серии образцов нерафинированного подсолнечного масла при повышении температуры растет быстрее, чем воспроизводимость серии образцов нерафинированного подсолнечного масла, достигая равного с ней значения при температуре $32{ }^{\circ} \mathrm{C} \pm 1{ }^{\circ} \mathrm{C}$. Это указывает на наличие связи между содержанием компонентов подсолнечного масла, удаляемых на стадии рафринирования, и структурным состоянием водноспиртовой эмульсии подсолнечного масла, существенно зависящем от изменения температуры. Изучение характера такой связи является важным этапом дальнейших исследований.

Таким образом, выбор оптимальных условий проведения калибровки мультисенсорной системы может быть обоснован закономерными данными, представленными на рисунке 3. Эти данные позволяют определить условия проведения калибровки с учётом способа получения ПРМ при наибольшей воспроизводимости, для достижения максимально возможной точности измерений в заданном интервале температур. Поскольку ранее было установлено, что при температуре $17^{\circ} \mathrm{C} \pm 1^{\circ} \mathrm{C}$ не удаётся сформировать математическую модель, позволяющую классифицировать результаты измерений для различных типов масел, а при температуре 22 
А. В. ФЁДОРОВ, Д. О. КИРСАНОВ, А. В. ЛЕГИН, И. А. ЛИСИЦЫНА, С. М. ВОЛКОВ, А. Г. НОВОСЁЛОВ, Ю. А. ПОЗДЕЕВА, Е. А. ЕЛОВЕГИНА

${ }^{\circ} \mathrm{C} \pm 1{ }^{\circ} \mathrm{C}$ такая процедура смогла быть реализована, то температура $22{ }^{\circ} \mathrm{C} \pm 1{ }^{\circ} \mathrm{C}$ может быть принята в качестве начала температурного интервала, в котором может быть проведена эффрективная калибровка мультисенсорной системы.

Измерение показателей качества ПРМ в температурном интервале от $22{ }^{\circ} \mathrm{C} \pm 1{ }^{\circ} \mathrm{C}$ до 26 ${ }^{\circ} \mathrm{C} \pm 1{ }^{\circ} \mathrm{C}$ необходимо проводить с использованием калибровок, построенных отдельно для образцов нерафинированного и рафинированного ПРМ, так как критерии воспроизводимости для обеих серий при этих температурах образуют два числовых подпространства, которые моделируются различными фуннкциями (2) и (3). При температуре, приблизительно равной 32 ${ }^{\circ} \mathrm{C} \pm 1{ }^{\circ} \mathrm{C}$, может быть использована общая для обеих серий образцов калибровка, т. к. функции (2) и (3) при этой температуре приблизительно равны друг другу. Причём численные значения среднего арифметического суммарного стандартного отклонения массива сенсоров для обеих фрункций при температуре $32{ }^{\circ} \mathrm{C} \pm 1^{\circ} \mathrm{C}$ имеют значительно меньшие значения по сравнению со значениями этого критерия воспроизводимости при более низких температурах. При температурах более $32{ }^{\circ} \mathrm{C} \pm 1{ }^{\circ} \mathrm{C}$ испарение спирта в исследованных водно-спиртовых эмульсиях становится достаточно интенсивным, что существенно снижает эффрективность использования мультисенсорной системы для измерения разности потенциалов в жиросодержащих водно-спиртовых эмульсиях подсолнечного масла.

Таким образом, эфрфективность калибровки мультисенсорной системы для нерафинированного и рафинированного подсолнечного масла при температуре $32^{\circ} \mathrm{C} \pm 1^{\circ} \mathrm{C}$ должна быть одинаковой при наилучшей воспроизводимости измерений разности потенциалов в водноспиртовых эмульсиях, полученных на основе образцов подсолнечного масла.

\section{выводы}

1. В ходе проведённых исследований был сформирован массив твердотельных сенсоров для измерения разности потенциалов водно-спиртовых эмульсий первого рода, приготовленных с использованием образцов нерафинированного и рафинированного подсолнечных масел.

2. При помощи сформированной мультисенсорной системы были измерены разности потенциалов в жиросодержащих водноспиртовых эмульсиях серии образцов нерафинированного и серии образцов рафиниро- ванного подсолнечных масел при температуpax $17{ }^{\circ} \mathrm{C} \pm 1{ }^{\circ} \mathrm{C}, 22{ }^{\circ} \mathrm{C} \pm 1{ }^{\circ} \mathrm{C}, 22^{\circ} \mathrm{C} \pm 1{ }^{\circ} \mathrm{C}$ n $32{ }^{\circ} \mathrm{C} \pm 1{ }^{\circ} \mathrm{C}$.

3. На основании полученных экспериментальных данных были рассчитаны: критерии воспроизводимости откликов сенсоров стандартные отклонения средних арифметических значений разности потенциалов параллельных измерений; суммарные стандартные отклонения сенсоров массива; средние значения суммарных стандартных отклонений разности потенциалов сенсоров массива для серий образцов нерафинированных подсолнечных масел и для серий образцов рафинированных подсолнечных масел при температурах $17^{\circ} \mathrm{C} \pm 1{ }^{\circ} \mathrm{C}, 22^{\circ} \mathrm{C} \pm 1^{\circ} \mathrm{C}, 22^{\circ} \mathrm{C}$ $\pm 1{ }^{\circ} \mathrm{C}$ и $32^{\circ} \mathrm{C} \pm 1^{\circ} \mathrm{C}$.

4. В исследованном температурном интервале зависимость среднего значения суммарных стандартных отклонений разности потенциалов сенсоров массива от температуры для серии образцов нерафинированных подсолнечных масел была аппроксимирована линейной функцией, уравнение (2), а для серии образцов нерафинированных подсолнечных масел - уравнение (3).

5. Поскольку математическое моделирование результатов измерений и стандартных отклонений, полученных при температуре 17 ${ }^{\circ} \mathrm{C} \pm 1{ }^{\circ} \mathrm{C}$, не позволило сформировать калибровочное пространство, а при температурах более $32{ }^{\circ} \mathrm{C} \pm 1{ }^{\circ} \mathrm{C}$ наблюдалось повышение интенсивности испарения спирта, нарушающее состав анализируемой гетерогенной жидкофразной системы, то сравнительный анализ функциональных зависимостей (2) и (3) для определения эфрфективности калибровок проводился в температурном интервале $22{ }^{\circ} \mathrm{C} \pm 1{ }^{\circ} \mathrm{C} \div 32{ }^{\circ} \mathrm{C} \pm 1{ }^{\circ} \mathrm{C}$. На основании полученных данных можно сделать вывод, что при проведении анализа в указанном температурном интервале необходимо проводить калибровку мультисенсорной системы для серии образцов нерафинированных подсолнечных масел и для серии образцов рафинированных подсолнечных масел отдельно друг от друга.

6. При температуре проведения анализа $32{ }^{\circ} \mathrm{C} \pm 1{ }^{\circ} \mathrm{C}$ может быть сформирована единая калибровка мультисенсорной системы как для серии образцов нерафинированного подсолнечного масла, так и для серии образцов рафинированного подсолнечного масла с наибольшей воспроизводимостью в исследованном температурном интервале.

7. Результаты данного этапа исследований свойств водно-спиртовых эмульсий под- 


\section{ИССЛЕДОВАНИЕ СВОЙСТВ ВОДНО-СПИРТОВЫХ ЭМУЛЬСИЙ ПОДСОЛНЕЧНОГО МАСЛА МУЛЬТИСЕНСОРНОЙ СИСТЕМОЙ ПРИ РАЗЛИЧНЫХ ТЕМПЕРАТУРАХ}

солнечного масла методом мультисенсорной потенциометрии могут быть использованы для решения аналогичных задач применительно к другим видами ПРМ.

\section{СПИСОК ЛИТЕРАТУРЫ}

1. Руководство по методам исследования, технохимическому контролю и учёту производства в масложировой промышленности / Ред. д.т.н. В. П. Ржехина, д.Т.н. А. Г. Сергеева. - Л., 1967. - Т.1, кн. 2. - 1053 c.

2. TP TC 024/2011.Технический регламент таможенного союза.

3. Масла растительные. Методы определения кислотного числа. ГОСТ 5476-80.

4. Жиры и масла животные и растительные. Определение перекисного числа потенциометрическим методом по конечной точке. ГОСТ Р ИСО 271072010.

5. Winquist, F. Anal.Chim.Acta. / F. Winquist, P. Wide, I. Lundstrom. - 1997. - V 21. - p. 357.

6. ГОСТ №31758- 2012 Жиры и масла животные и растительные. Определение устойчивости к окислению (ускоренное испытание на окисление).

7. Кучменко, Т. А. Оценка качества масла грецкого ореха по сигналам анализатора «электронный нос» / Т. А. Кучменко // Масла и жиры. - 2015. - № 910.

8. Современные аспекты технологии и экспертизы растительных масел. «Санкт-Петербургский торгово-экономический институт» - С-Пб., 2012.

9. Kovalskiy, I. Sensor for determining the composition of fluid. IEEE WORKSHOP 2016. Industrial and Medikal measurement and Sensor Technology / I. Kovalskiy, G. Lukyanov, A. Fedorov, S. Volkov // Mulheim an der Rhur, 2016.

10. Власов, Ю. Г. Мультисенсорные системы типа электронный язык - новые возможности создания и применения химических сенсоров / Ю. Г. Власов, А. В. Легин, А. М. Рудницкая // Успехи химии, 2006. - 75 (2).

11. Legin, A. Electronic tonque distinquishes rancidity of vegetable oils, in Proceedings of Sensors / A. Legin, A. Rudnitskaya, B. Seleznev, A. Ivanov et al. -2001, 8-10 May, Nuremberg, Germany. - p. 47.

12. Никольский, Б. П. Ионоселективные электроды / Б. П. Никольский, Е. А. Матерова. - Л. : Химия, 1980. -240 c.

13. Vlasov, Yu. Chalcogenide glass chemical sensors : Research and analytical applications / Yu. Vlasov, E. A. Bychkov, A. V. Legin. - Talanta. - 1994. - 41(6). - p. 1059-1063.

14. Esbensen, K. Multivariate Analysis in Practice CAMO ASA / K. Esbensen, S. Schonkopf, T. Midtgaard . Norvey, 1998.

15. Dias, L. G. Single-cultivar extra virgin olive classifiration using f potentiometric electronic tongue / L. G. Dias, A. Fernandes, A. S. A. Veloso et al. // European Food Research and Technology. - 2016. - V. 242(2). - p. 259270.
16. Veloso, A. S. A. Sensory intensity assessment of olive oils using an electronic tongue / A. S. A. Veloso, L. G. Dias, N. Rodrigues, J. A. Pereira, A. M. Peres // Talanta. 2016. - V. 146. - p. 585-593

17. Научный совет по аналитической химии ИХНМ РАН. Проблемы аналитической химии. Т.14. Химические сенсоры / Под редакцией Ю. Г. Власова. - М. : Наука, 2010. - 399 с.

18. Власов, Ю. Г. Электронный язык - система химических сенсоров для анализа водных сред / Ю. Г. Власов, А. В. Легин, А. М. Рудницкая // Российский химический журнал. - 2008. - T. LII. - № 2.

19. Брайен, Р. О. Жиры и масла. Производство, состав и свойства, применение / Р. О. Брайен. - СПб. : «Профрессия», 2007.- 751 с.

20. Рудаков, О. Б. Жиры. Химический состав и экспертиза качества. Методы определения качества / О. Б. Рудаков, А. Н. Пономарёв, К. К. Полянский, А. В. Любарь. - М. : «Де Ли принт», 2005. - 312 с.

Федоров Александр Валентинович, заведующий кафредрой «Пищевой биотехнологии продуктов из растительного сырья» Универcumema ИТМО, 191002, СПб, ул. Ломоносова, 9, тел. 8-921-304-41-08, e-mail: fedorov@vniig.org

Кирсанов Дмитрий Олегович, профрессор кафеедры «Аналитической химии» Инстиmута химии СПбГУ, 198504, СПб, Петергоф, Университетский пр-m, 26, e-mail: d.kirsanov@gmail.com

Легин Андрей Владимирович, доцент кафредры «Радиохимии» Института химии СПбГУ, 198504, СПб, Петергоф, Университетский пр-m, 26 e-mail: andrey.legin@gmail.com

Лисицына Ирина Анатольевна, заведующая отделом «Исследования жиров» ВНИИЖиров СПб. 191119, СПб, ул. Черняховского, 10, тел. 8-812-572-41-93, e-mail: research@vniig.org

Волоков Сергей Михайлович, старший научный сотрудник ВНИИЖиров СПб, 191119, СПб, ул. Черняховского, 10, тел. 8-911-701-6106, e-mail: volkovsm@vniig.org

Новоселов Александр Геннадиевич, профрессор кафредры «Прочессов и аппаратов пищевых производств» Университета ИТМО, 191002, СПб, ул. Ломоносова, 9, тел. 8-921-90083-35, e-mail:dekrosh@mail.ru

Поздеева Юлия Васильевна, магистр гр. Т4245 кафедры «Процессов и аппаратов пищевых производств» Университета ИТМО, 191002, СПб, ул. Ломоносова, 9, e-mail: boxxx13@mail.ru

Еловегина Елена Александровна, магистр гр. T4245 кафредры «Процессов и аппаратов пищевых производств» Университета ИТМО, 191002, СПб, ул. Ломоносова, 9, e-mail: elovegina1994@mail.ru 